\title{
INFORMATION PANELS AND SCENIC ILLUMINATION AS IMPORTANT ELEMENTS OF RUIN PRESENTATION
}

\section{NOVOTNÝ Jakub ${ }^{1}$, MACHOVÁ Dita ${ }^{2}$}

${ }^{1}$ Jakub Novotný, Institute of Theoretical and Applied Mechanics of the Czech Academy of Sciences https://orcid.org/0000-0003-2162-3218

2 Dita Machová, Institute of Theoretical and Applied Mechanics of the Czech Academy of Sciences https://orcid.org/0000-0001-9956-7282

ABSTRACT: This paper is focused on the issue of information panels and the illumination of monuments, especially ruins. First, methodological recommendations of ICOMOS Charter for the Interpretation and Presentation of Cultural Heritage Sites are mentioned as it is necessary to follow the recommendations when planning and implementing any interpretive infrastructure. There follows a brief characteristic of the function, intervention, positive and negative of the information panels as important elements of the interpretative infrastructure. Similarly, scenic illumination of monuments is presented. Two case studies of installation of information panels are than described - Jihlava Town Fortification (CZ) and Remains of Slav Hill Fort. The conclusion than offers methodological steps for the choice of solution and realisation of interpretive infrastructure.

KEY WORDS: Information panel, scenic illumination, monument, ruin 


\section{Introduction}

Preservation, maintenance and management of ruins need surely complex and multidisciplinary approach. It is composed as a mosaic of many pieces; their interaction produces the resulting work. In the case of ruins, it is preserved object, which fulfil the appropriate purpose within the specified use. Whether it is a target object within a tourist destination or an object used for other economic (commercial) or social activities. For ancient and medieval ruins, it is always true that regardless of location, condition and use, it is a remarkable monument. Therefore, there is a need to draw attention of targeted and casual visitor to this fact.

In this paper, we will focus on the issue of information panels (boards) for historical ruins and, in addition, on the issues of scenic illumination. This is an area that is not in the scientific literature discussed in same intensity as preservation issues. It does not require such technical complexity and methodical approach but may in the final presentation of the monuments play an important role and is an integral part of the architectural renovation solution. It is not, on the other hand, an area that is totally neglected, at least in general methodological recommendations. This is particularly concerned in the ICOMOS Charter for the Interpretation and Presentation of Cultural Heritage Sites. That is why we first draw a closer look at the structure and recommendations of the Charter, then we will focus on the issue of information panels and illumination, and we will supplement it with several case studies.

\section{The ICOMOS Charter for the Interpretation and Presentation of Cultural Heritage Sites}

Information panels and scenic illumination are part of the interpretation and presentation of monuments and belong to its interpretive infrastructure. The Charter establishes 7 basic principles, upon which interpretation and presentation should be based ${ }^{2}$ :

Principle 1: Access and Understanding - Interpretation and presentation programmes should facilitate physical and intellectual access by the public to cultural heritage sites.

Principle 2: Information Sources - Interpretation and presentation should be based on evidence gathered through accepted scientific and scholarly methods as well as from living cultural traditions.

Principle 3: Attention to Setting and Context - Interpretation and presentation of cultural heritage sites should relate to their wider social, cultural, historical, and natural contexts and settings.

Principle 4: Preservation of Authenticity Principle - Interpretation and presentation of cultural heritage sites must respect the basic tenets of authenticity in the spirit of the ICOMOS Nara Document On Authenticity (ICOMOS, 1994).

1 The ICOMOS Charter for the Interpretation and Presentation of Cultural Heritage Sites, ICOMOS 2008, http://icip.icomos.org/downloads/ICOMOS_Interpretation_Charter_ENG_04_10_08.pdf.

2 Ibidem. 
Principle 5: Planning for Sustainability - The interpretation plan for a cultural heritage site must be sensitive to its natural and cultural environment, with social, financial, and environmental sustainability among its central goals.

Principle 6: Concern for Inclusiveness - Interpretation and presentation of cultural heritage sites must be the result of meaningful collaboration between heritage professionals, host and associated communities, and other stakeholders.

Principle 7: Importance of Research, Training, and Evaluation - Continuing research, training, and evaluation are essential components of the interpretation of a cultural heritage site.

All the seven principles are described in more detail in the Charter and constitute an appropriate methodical guideline that can be to a certain extent practically used for specific tools of interpretive infrastructure such as information panels.

\section{Information panels}

The information panels belong to modern, but from the point of view of monument presentation, the traditional (or better to say the most used) accompanying interpretation facility. It is necessary to realize that the information panels are always an artificially added component and thus a historically inauthentic element of the given monument. The first four are the most important of mentioned ICOMOS principles for interpretation and presentation of cultural heritage sites.

Information panels create a group of small size permanent installations designed for an economical and attractive way of displaying information for visitors. Information panels are usable for the most of immovable historical objects including ruins and archaeological sites. They primarily offer a more complete picture of the site, its history, or local attractions.

The technical solution can take various forms and there is a wide offer of this solution on the market, but they are usually orderly produced. The most common types of information panels are: 
- Stand-alone boards from different materials

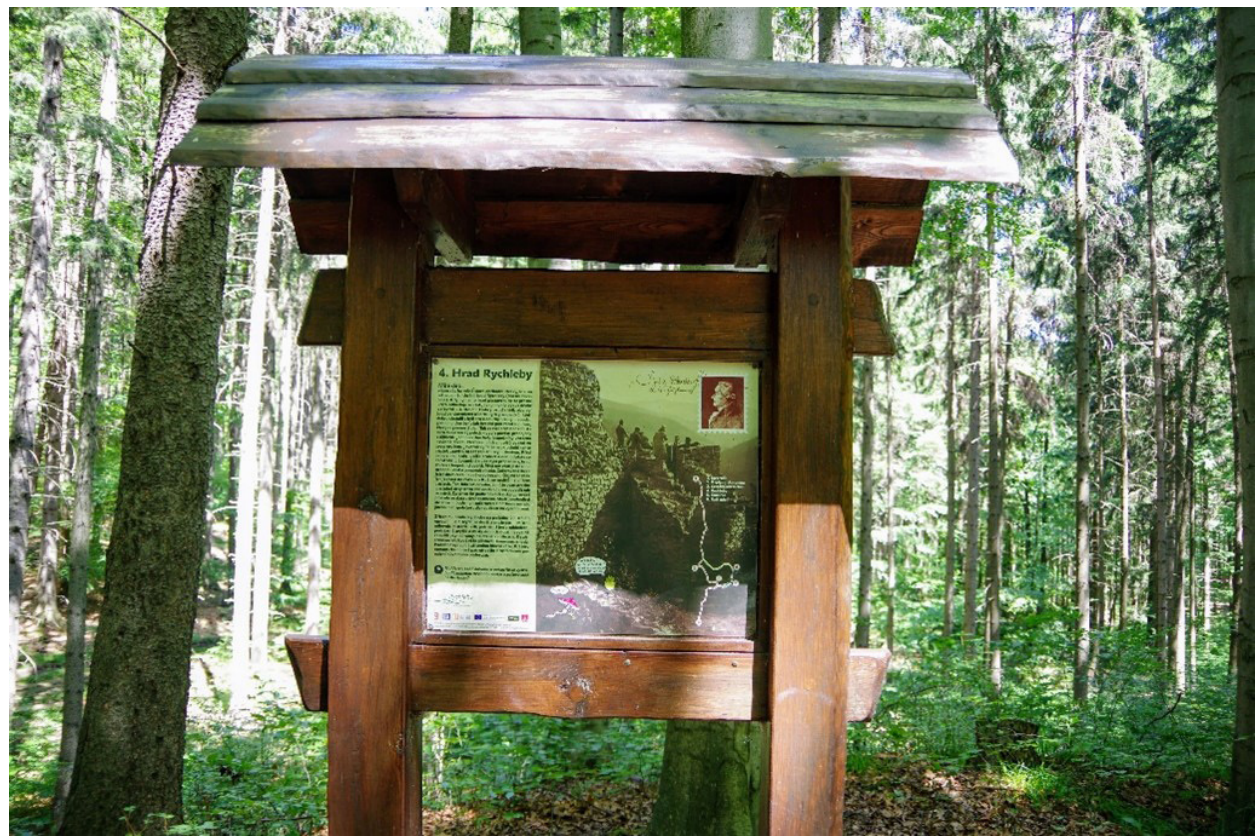

Fig. 1 Stand-alone board - ruin of castel Rychleby, CZ (J. Novotný)

- Tables on the wall made from different materials

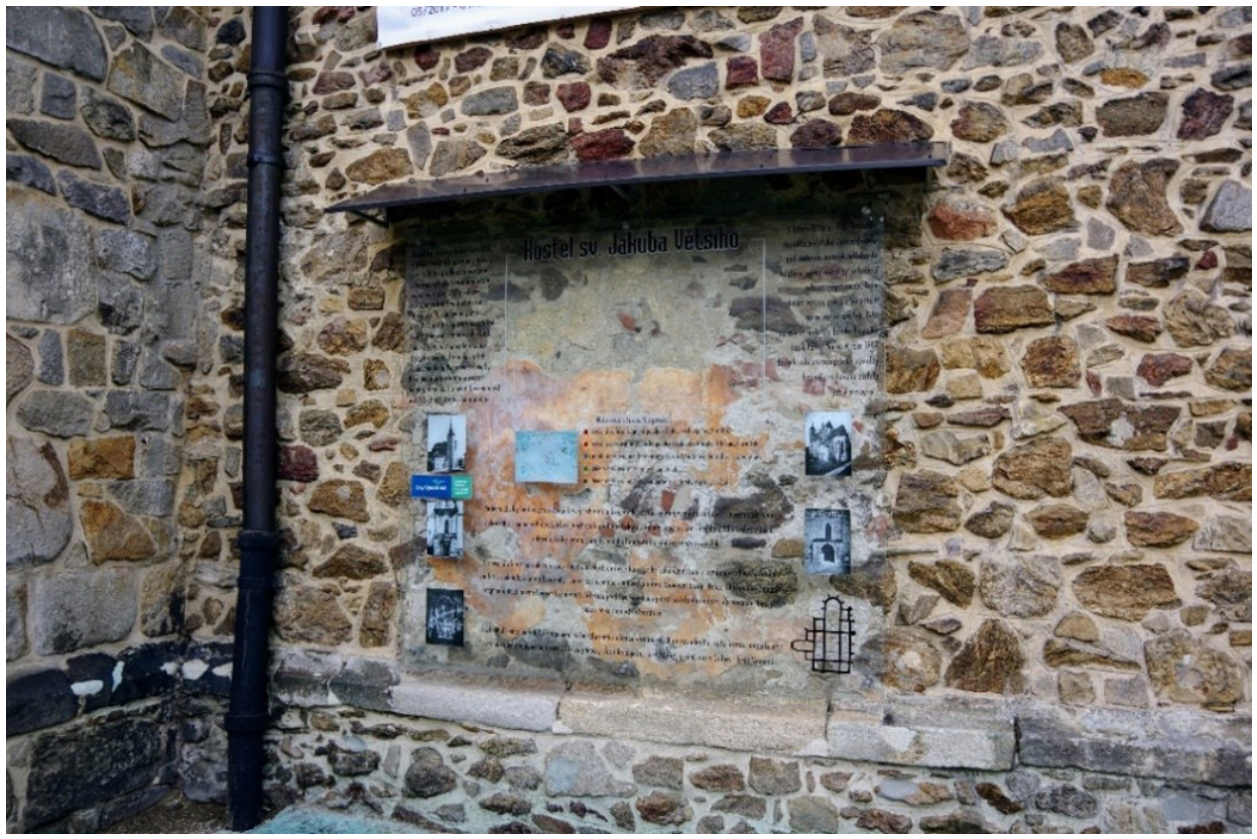

Fig. 2 Transparent information board on the wall of the St. James Church in Jihlava, CZ (J. Novotný) 
- Posters made of synthetic fabrics

- Paving tiles with texts, maps or pictures

- Stand-alone posts/totems; combination with audio guide is possible

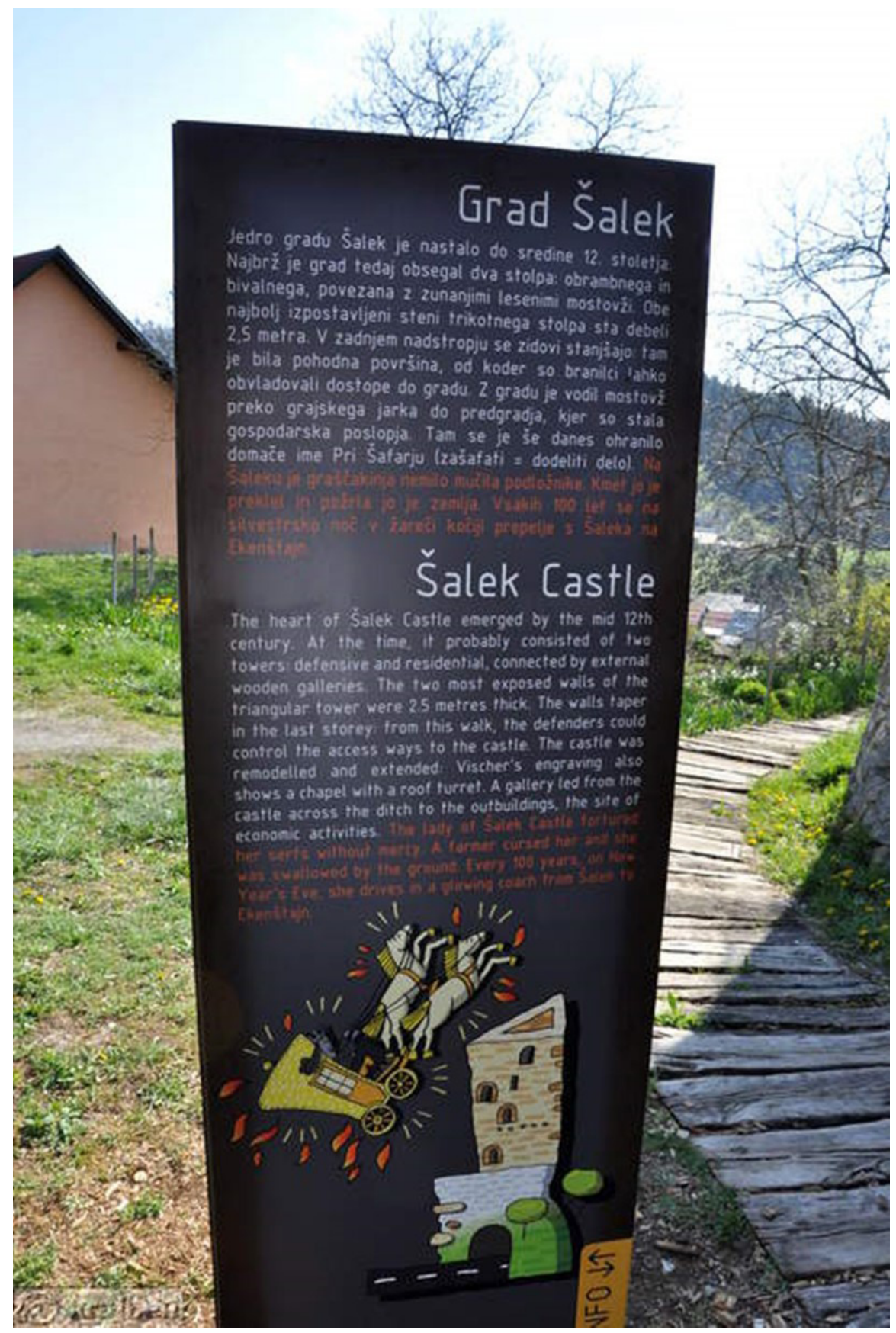

Fig. 3 Šalek Castl info post, SLO (http://kraji.eu/slovenija/saleski_grad/eng) 
- Visualization or way finder models with texts

- Haptic scale models for blind people

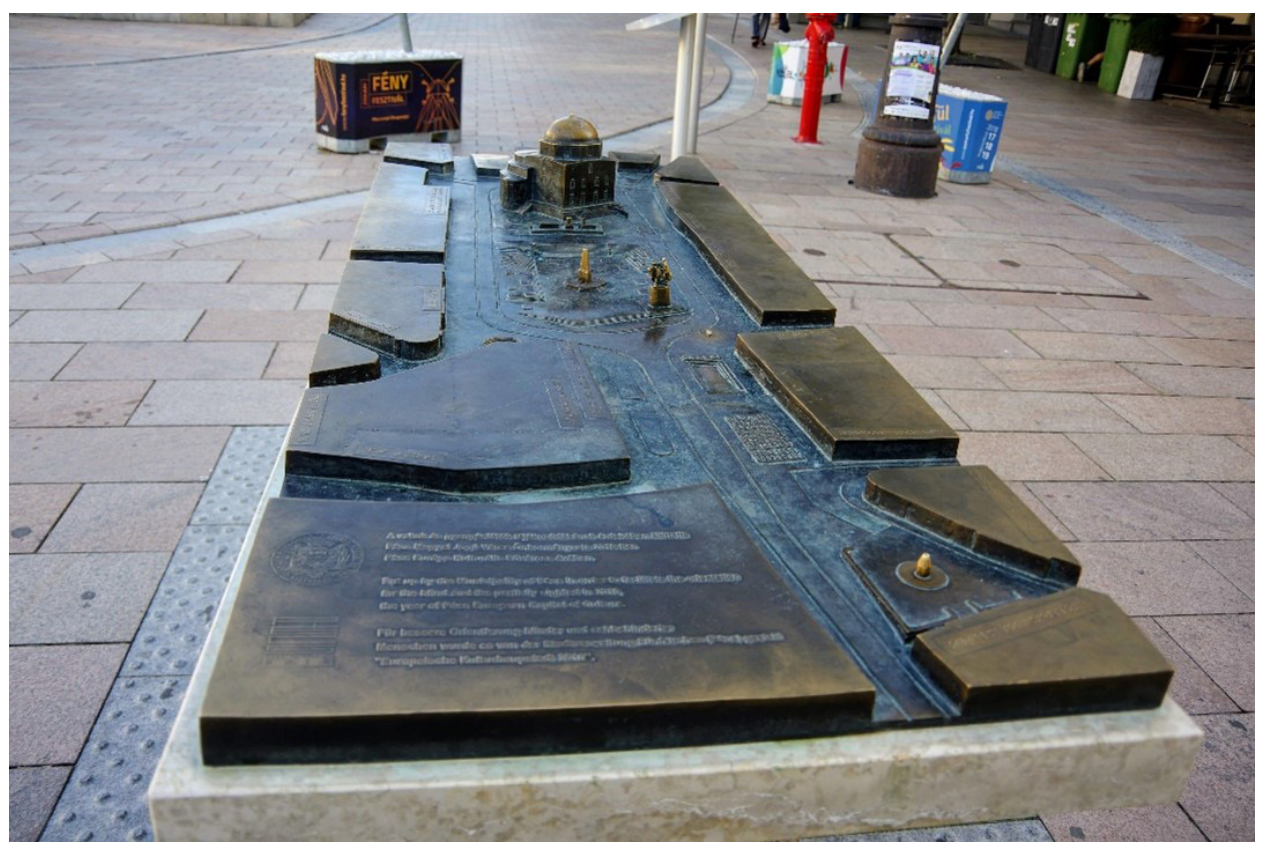

Fig. 4 Haptic model of the main square in Pécs, H (J. Novotný)

Volume of information that can be presented is limited for standard (ie passive) information panels. New technologies and Internet connectivity bring new possibilities. Information panels can be combined with other forms of heritage interpretations (webpages, smart devices applications, leaflets, etc.).

As we have mentioned above, information panels are unauthentic parts of the monument. Their intervention rate is depending on locality and specific technical solution, but mostly none or minimal as concrete base blocks of posts, fastening screws or anchors when placed on the walls. Main advantages of this kind of interpretive infrastructure are since it is a simple and mostly relatively inexpensive in situ publication of basic information about the object. Maps and visualizations of original state can be easily compared with actual state of the object - this is especially true for ruins.

Main negatives or risks are these: Regular maintenance is needful. It could be endangered by vandalism, especially in outlying localities. Inappropriate technical solutions, designs, or locations may disrupt genius loci of a site or spoil photographs wished by visitors. Transparent material for boards minimizes visual impact but such panels are harder to read. 


\section{Illumination}

Another kind of modern and supplementary infrastructure is scenic illumination of monuments. Illumination is the ephemeral partner of architecture, and lighting design has become a seamless and harmonious extension. Light, shade and gradient of light are important factors that reveal the shape and form of objects in a dark environment according to the direction of light.

Lighting of cultural heritage is one of the area's most challenging and complex for lighting designers because of the multiplicity of objectives that should be pursued in the project. The lighting design recommendations related to physical appearance, surrounding areas and lighting design techniques. Artificial lighting permits the creation of scenes that complement and lead to other readings.

Illumination maximises the visualisation of the monument and its surroundings. The lighting reflects the modern role of the historic buildings, where night-time visitors are encouraged, and where special events can have a customized lighting system to add aesthetic appeal or highlight areas of interest.

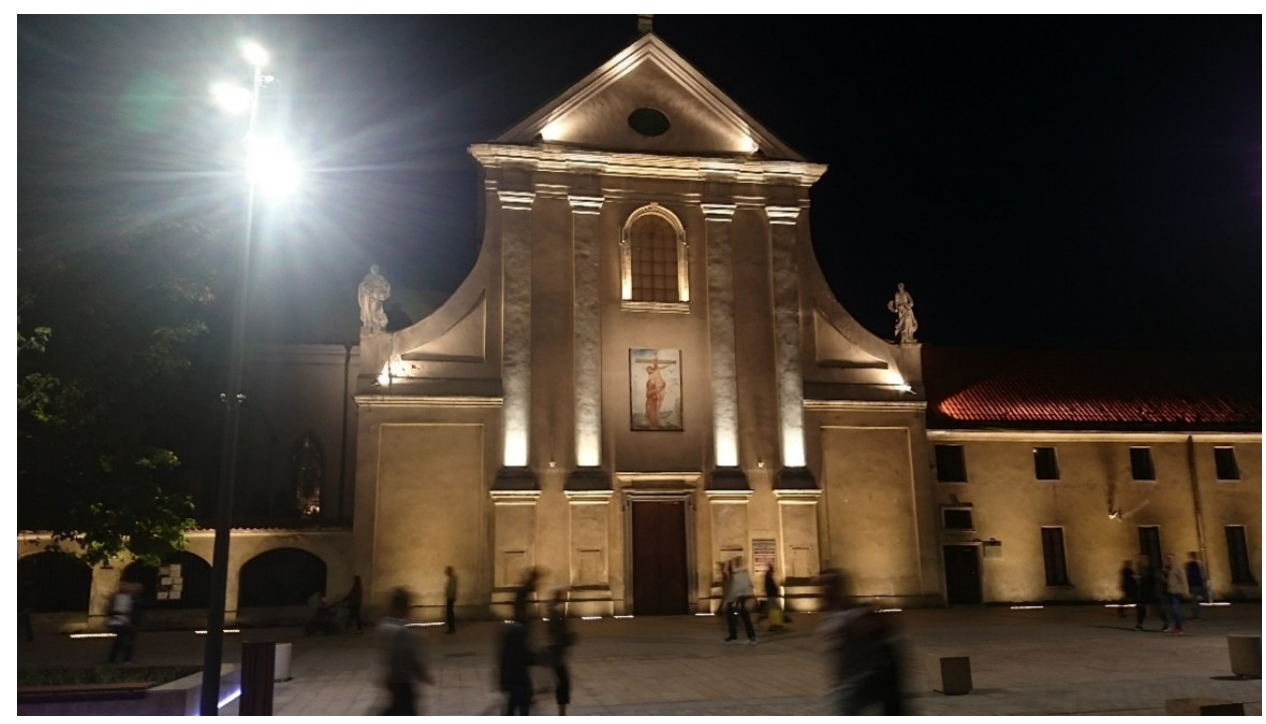

Fig. 5 Balanced illumination of the church, Lublin, PL (J. Novotný)

Illumination is also mostly unauthentic parts of the monument. Its intervention rate on monuments themselves is mostly insignificant. The impact is more on the environment. I $\mathrm{n}$ developed countries, external lighting of objects of cultural heritage causes 5\% to $20 \%$ of total light pollution. Very often, $60 \%$ to $80 \%$ of the entire light flux misses the facade and is emitted into the sky and the surroundings.

Only a few years ago, LED lamps became sufficiently effective for exterior lighting. The technology has been improving and will probably dominate indoor and outdoor lighting. LED ground lights have the advantage of being discreet and when located next to the building can minimise problems such as glare and being obstructive. 
The advantage of illumination is also its use for short-term performance such as videomapping. It will attract attention to the monument of a larger number of people within a limited timeframe and will not interfere with the long-term presentation of the monument.

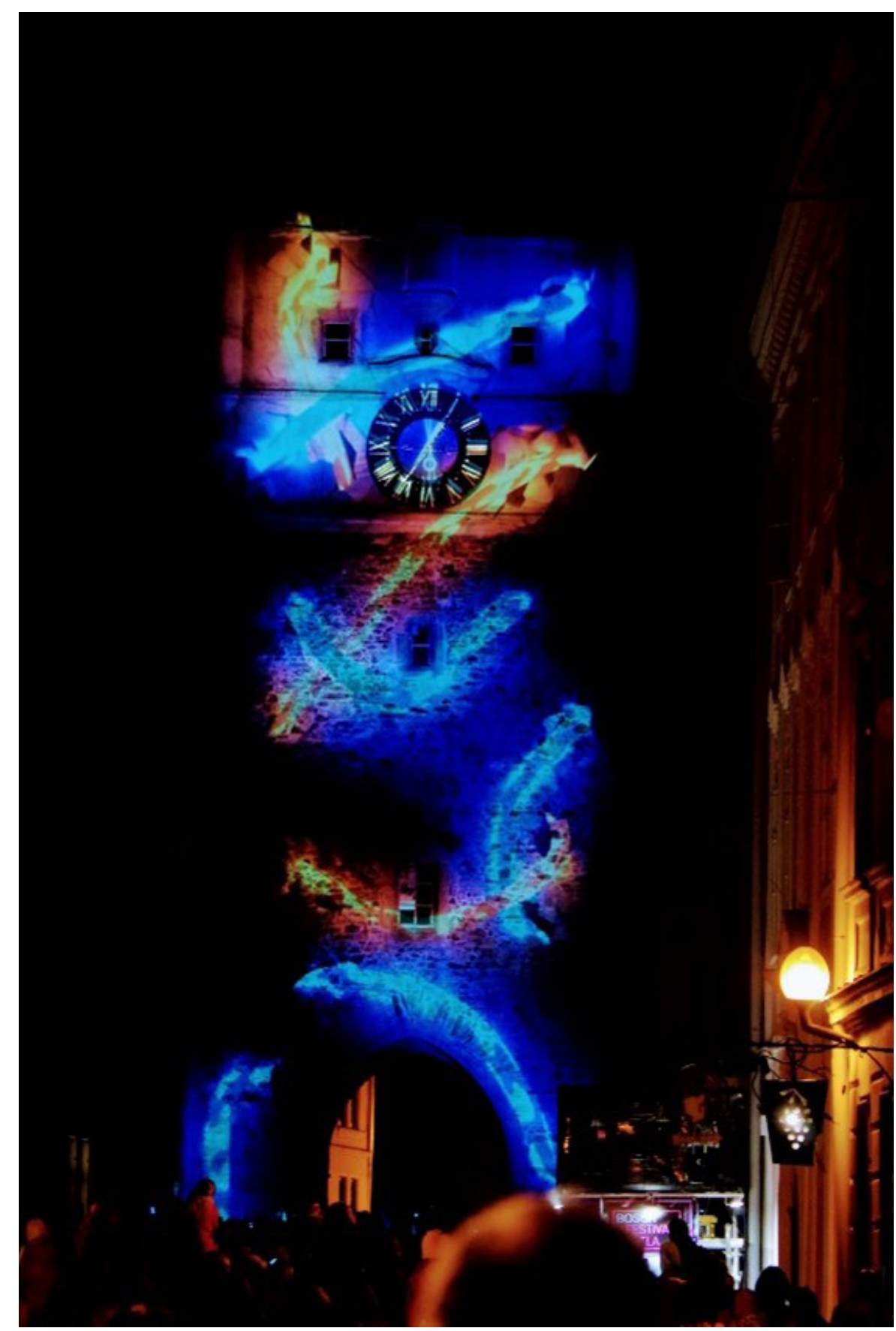

Fig. 6 Vidoemapping performance on remains of the medieval fortifications of Jihlava, CZ (J. Novotný) 
But there are also significant negatives and risks of every artificial illumination. No lighting is nature-friendly. The colour combination in the lighting systems provides important visual and aesthetic stresses. Light pollution can reduce human health. In current practice of facade lighting for building, much of the produced light misses the target area, and facade luminance is often far larger than is necessary. This results in a dramatic waste of electrical energy.

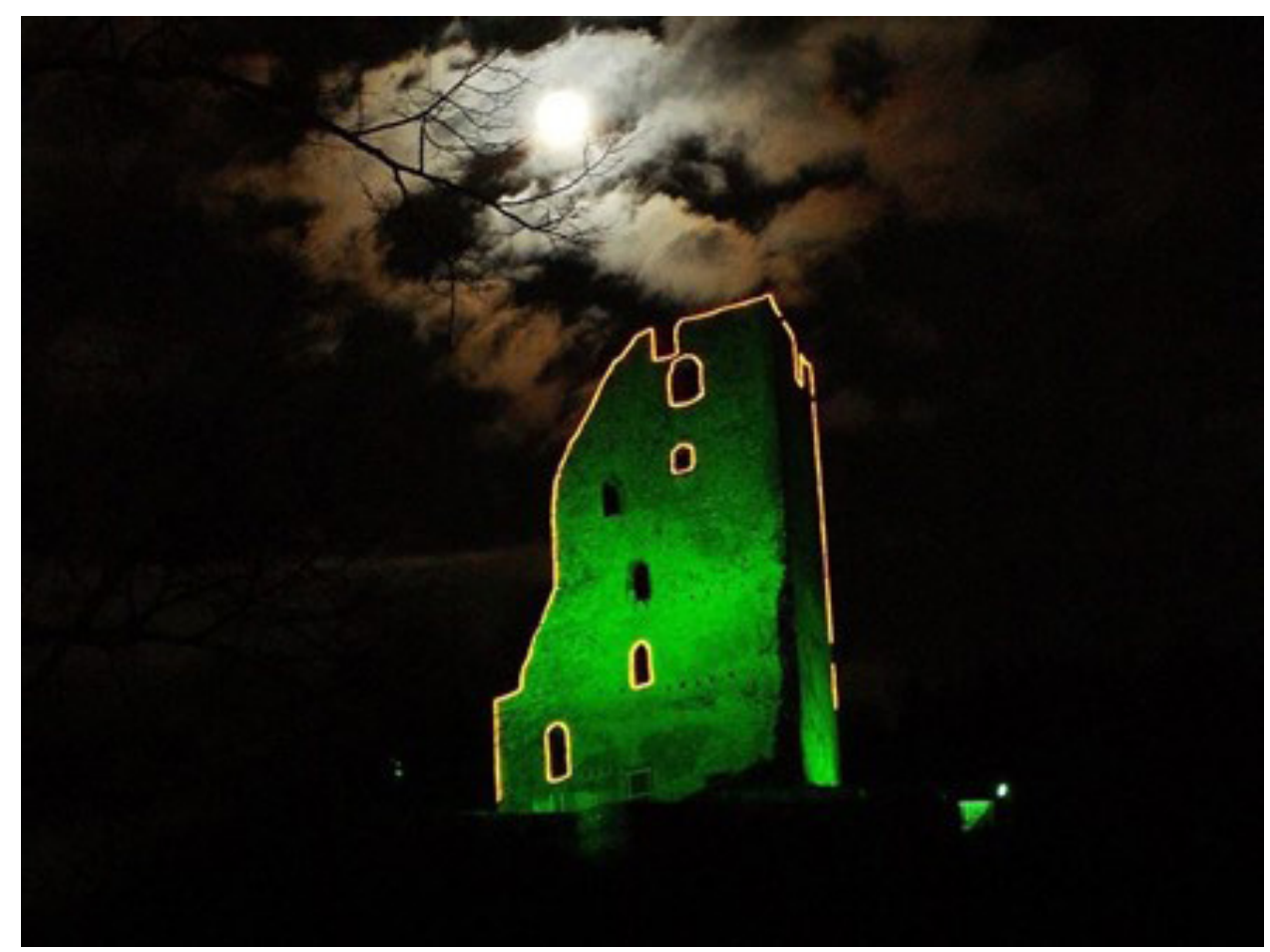

Fig. 7 Questionable illumination of Šalek castle, SLO (https://welcomemap.si/place/salek-castle/)

\section{Two case studies of information panels}

There will be presented two case studies of installation of information panels in this part. We will focus on standard solution in case of Jihlava Town Fortification (CZ) and uniquely and artistically designed solution in case of Remains of Slav Hill Fort, Libice nad Cidlinou (CZ).

\section{Jihlava Town Fortification}

Presented remnants of medieval town fortification are located in Jihlava, Vysočina Region, Czech Republic. Management of this historical site is provided by City of Jihlava. There is a touristically accessible circuit to the remnants of the mediaeval town fortifications. Heritage interpretation is intended for visitors to the city. Basic information on the history of town fortification is secured by system of 9 panels with 4 masonry screws on each of them. The panels were installed in the year 2013.

Information system enables tourists to follow a trail on the history of the town fortifications. Interpretation panels are designed in sober colours and provide information in Czech, English 


\section{Jakub Novotný, Dita Machová}

and German languages. The chosen design on one side does not disturb the objects themselves, but it is not an original or imaginative solution. Additionally, panels are often the target of sprayers, some are known to have effects of weather.

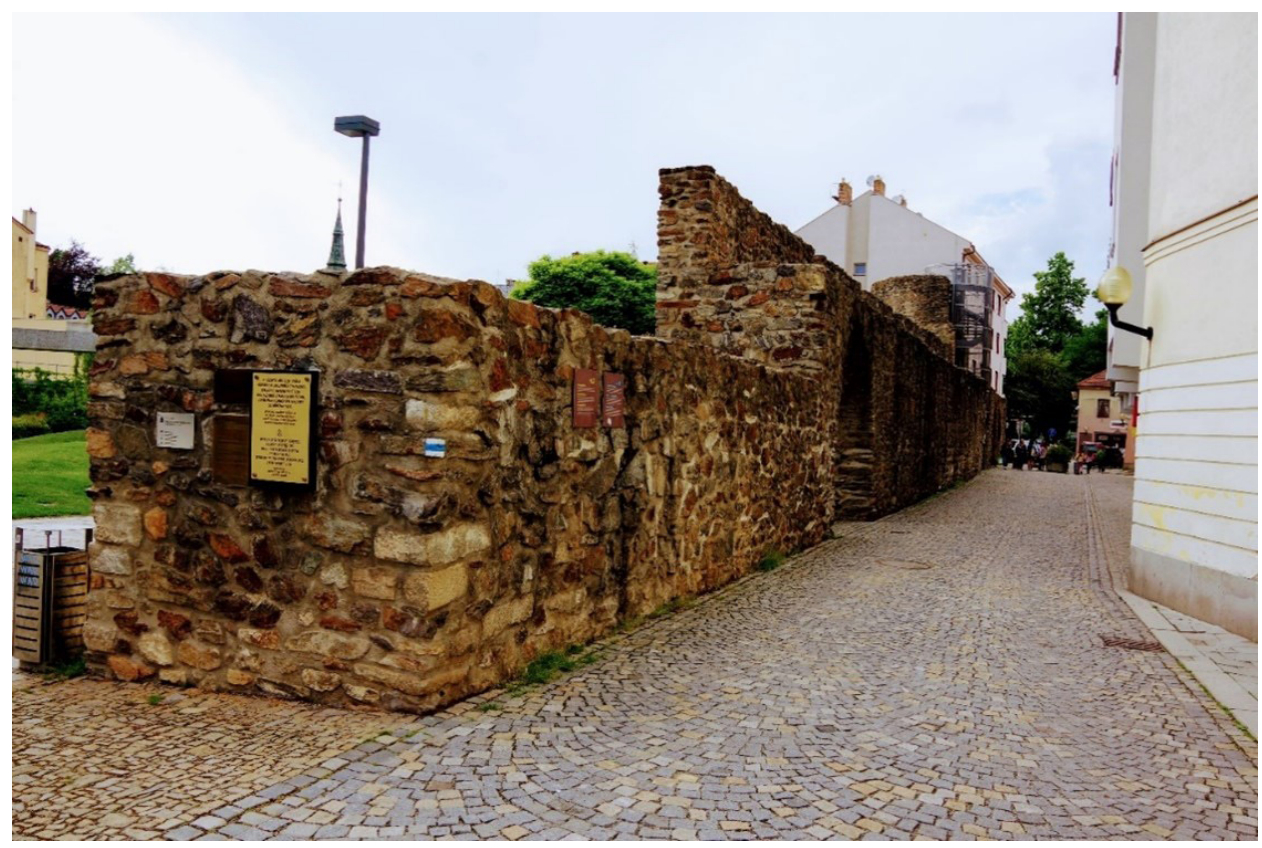

Fig. 8 Remnants of the mediaeval town fortifications Jihlava, CZ (J. Novotný)

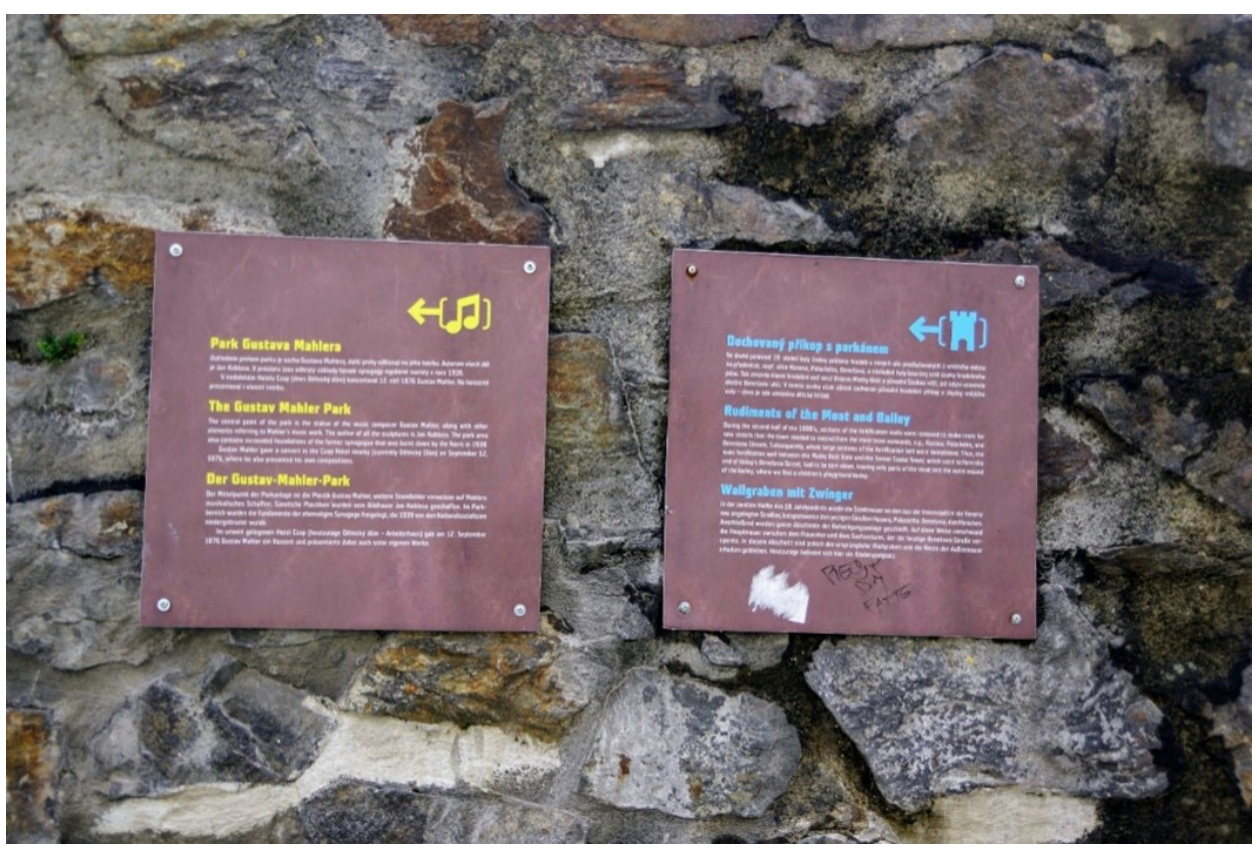

Fig. 9 Deatil of information panels, mediaeval town fortifications Jihlava, CZ (J. Novotný) 


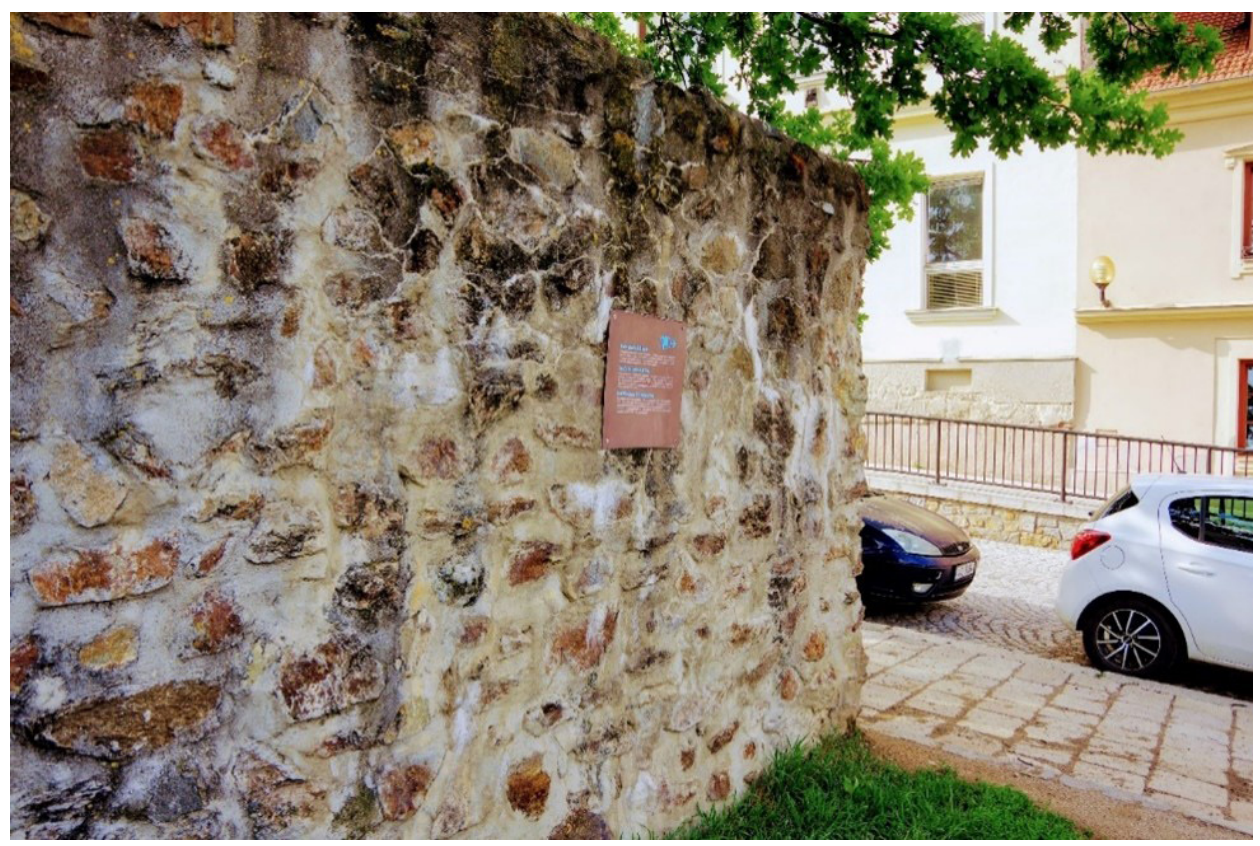

Fig. 10 Remnants of the mediaeval town fortifications Jihlava, south part, CZ (J. Novotný)

\section{Remnants of Slav Hill Fort}

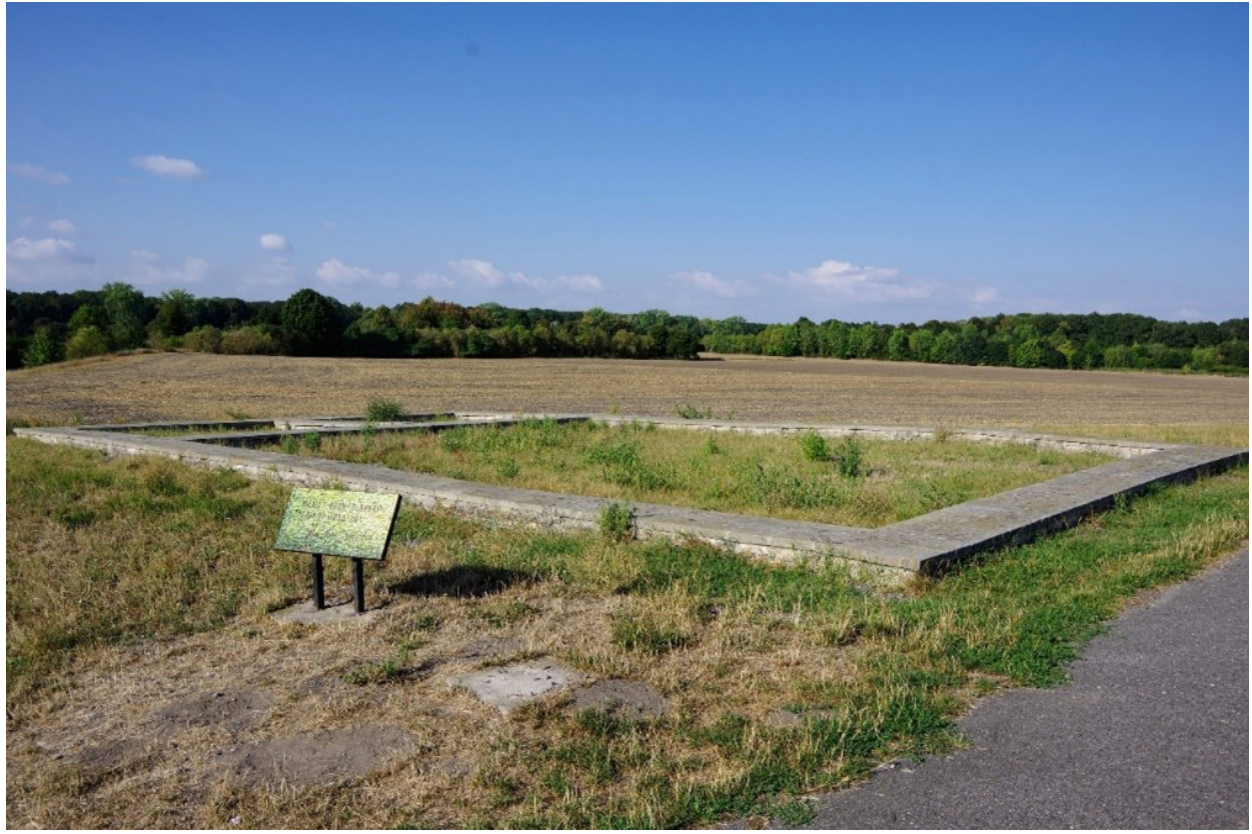

Fig. 11 A view of part of the fort with the single panel, Libice nad Cidlinou, CZ (J. Novotný) 
There are very special information panels for remnants of Slav Hill Fort in Libice nad Cidlinou, Czech Republic. This panels are made in "Byzantine style" by the road to the fortified settlement (eastwards from the village, westwards from the fortified settlement). The texts are in several languages and some of panels present plans of the fort and the visualisation of the typical findings. Mosaic information panels are from year 1965. The author of this mosaic installation is Zdeněk Rossman. The information panels represent an unique artwork which is itself recorded in the Czech Republic's catalogue of monuments, even though it is not a protected monument.

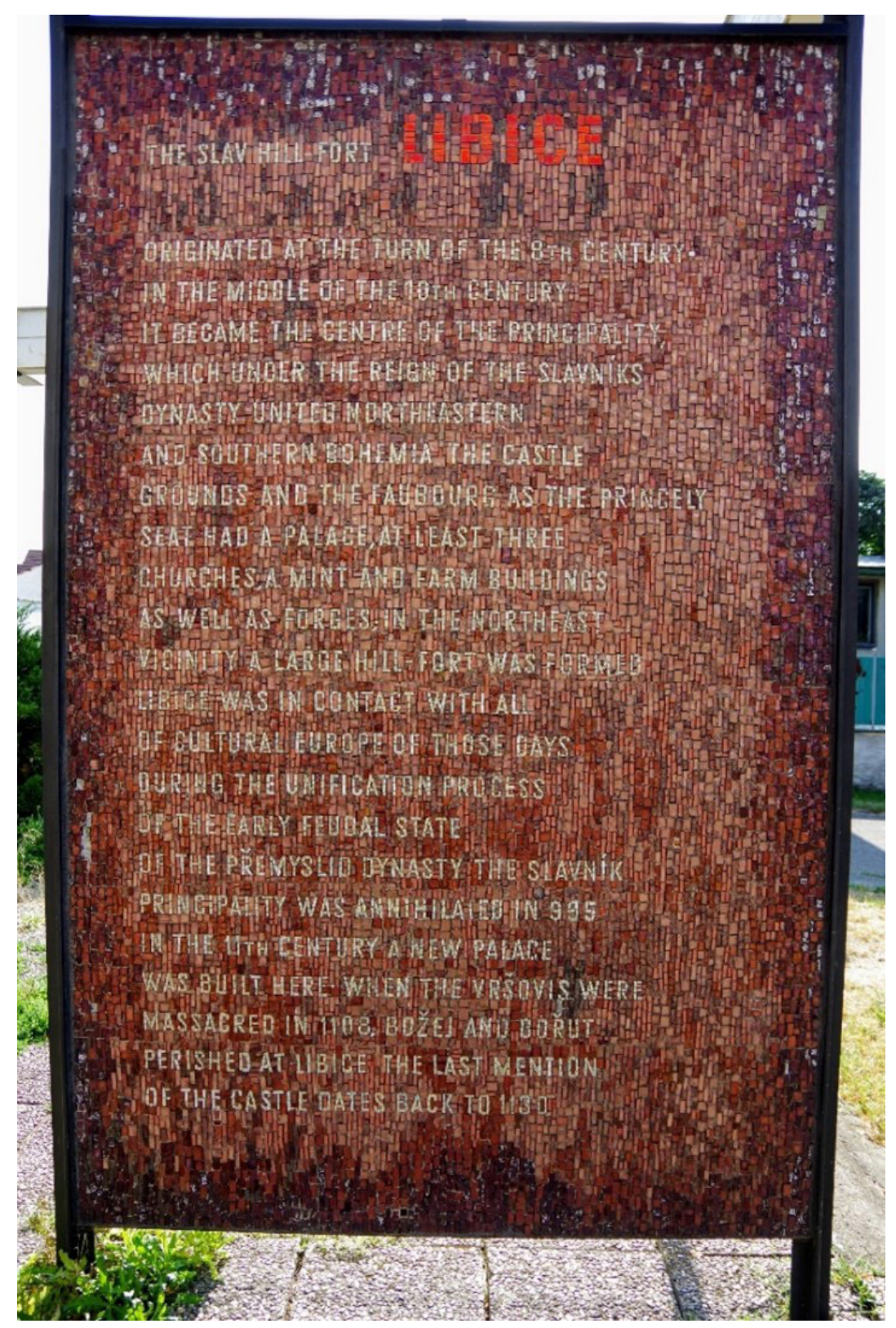

Fig. 12 Mosaic information panel with text, Libice nad Cidlinou, CZ (J. Novotný) 


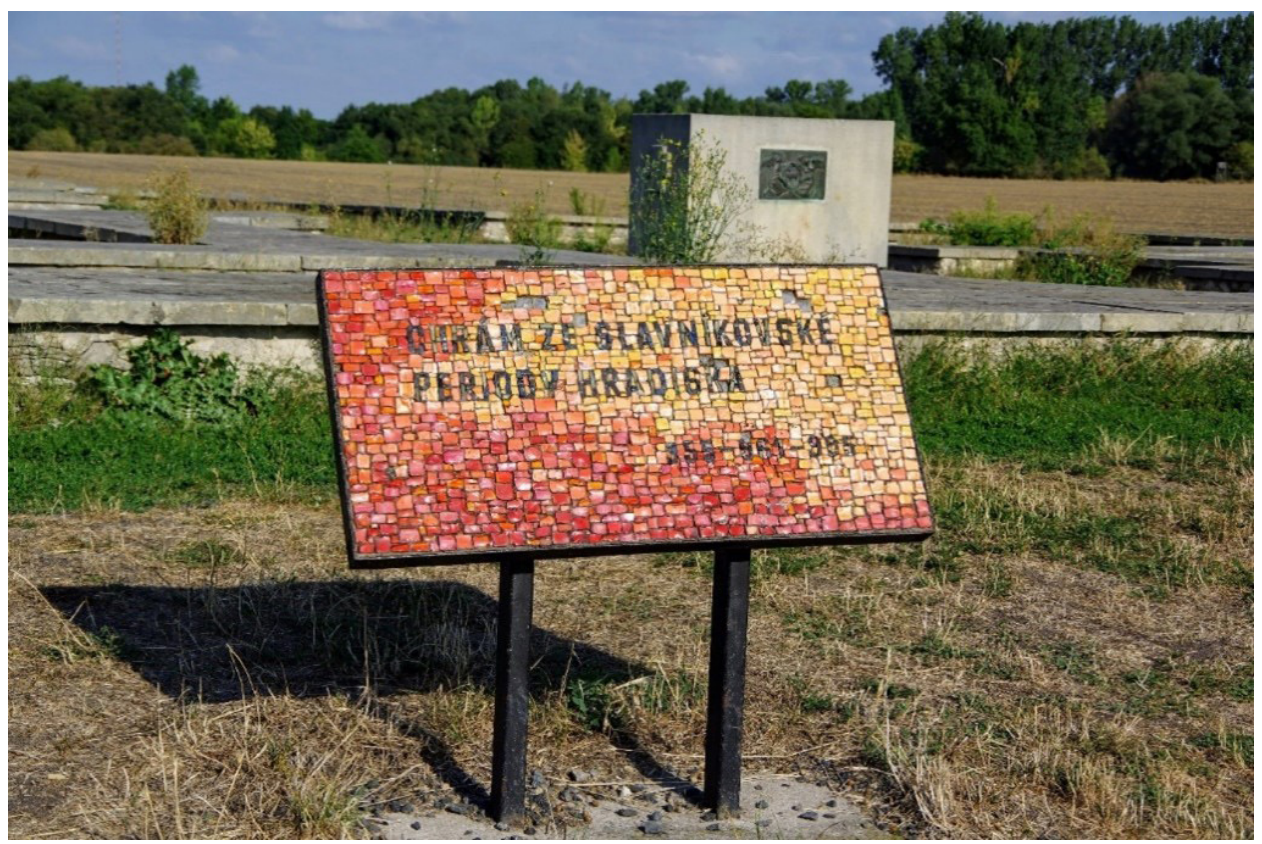

Fig. 13 Detail of the single panel, Libice nad Cidlinou, CZ (J. Novotný)

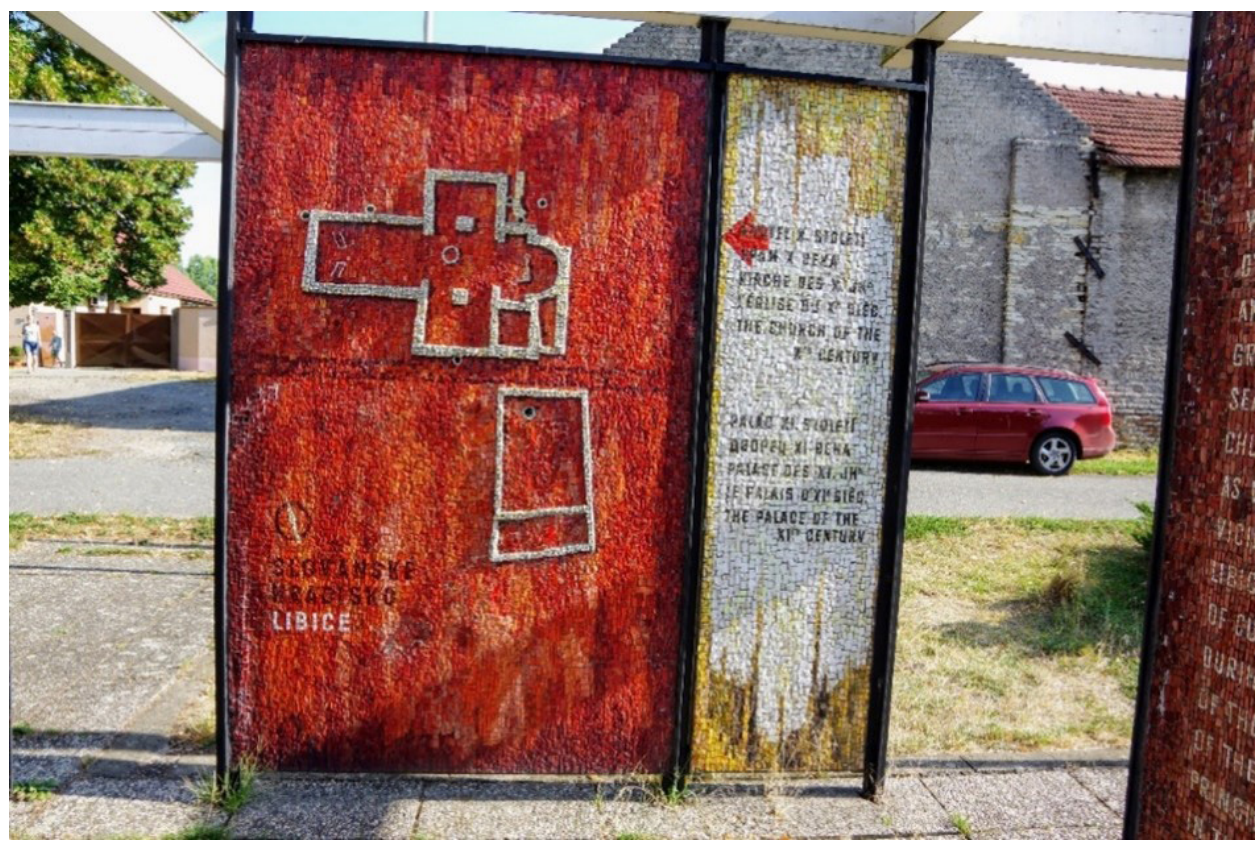

Fig. 14 Mosaic information panel with ground plan of the fort, Libice nad Cidlinou, CZ (J. Novotný) 


\section{Jakub Novotný, Dita Machová}

\section{Conclusion}

In this paper, we have focused on the issue of information panels and the scenic illumination of monuments, especially ruins. When planning and implementing any interpretive infrastructure, it is advisable to follow the recommendations of ICOMOS Charter for the Interpretation and Presentation of Cultural Heritage Sites.

The choice of solution and subsequent realisation can be schematized into the following methodical steps:

1. Analysis of the type and location of the monument

2. Goals of interpretation

3. Assembling resources about monument that can be used for interpretation

4. Determination of economic and technical constraints

5. Choosing the most suitable solution

6. Check compliance with ICOMOS principles

7. Implementation of interpretative infrastructure

8. Maintenance of interpretative infrastructure

At the very end, it is needed to reiterate that information panels and illuminations can significantly increase the visitor value of the monument, but in the case of an inappropriately solution chosen, they may interfere with the overall impression and authenticity. It is therefore necessary to give them proper attention and to proceed fully methodically in their selection and implementation.

\section{Acknowledgement}

Presented results were achieved with the financial support of Interreg Central Europe programme (project CE 902) within activities of Centre of Excellence Telč supported by the Ministry of Education, Youth and Sports under the NPU I programme (project LO1219). 


\section{Bibliography}

Guilhot A., The architectural lighting: a new urban writing. Urban night space, Conference proceedings, 2006.

http://svetelneznecisteni.cz/

https://www.jihlava.cz/en/vismo/o_utvar.asp?id_org=100405\&id_u=1049\&p1=2679

Interpretation Handbook and Standard: Distilling the essence, Wellington: Department of Conservation, 2005, ISBN 0-478-22572-5.

Irish Walled Towns Network: Bored of boards! Ideas for interpreting heritage sites. The Heritage Council, 2016, https://www.heritagecouncil.ie/content/files/bored_of_boards_1mb.pdf

Kyba C. CM, et al., A shining example of sustainable church lighting using the EcoSky LED: 96\% reduction in energy consumption, and dramatic reduction of light pollution, International Journal of Sustainable Lighting 19.2 (2017), pp. 132-132.

The ICOMOS Charter for the Interpretation and Presentation of Cultural Heritage Sites, ICOMOS 2008, http://icip.icomos.org/downloads/ICOMOS_Interpretation_Charter_ ENG_04_10_08.pdf

The Nara Document On Authenticity, ICOMOS 1994, https://www.icomos.org/charters/nara-e. pdf 